\title{
СОЦИАЛЬНОЕ ПРЕДПРИНИМАТЕЛЬСТВО В ВЕЛИКОБРИТАНИИ: ОСОБЕННОСТИ И ТЕНДЕНЦИИ РАЗВИТИЯ
}

\section{SOCIAL ENTREPRENEURSHIP IN UNITED KINGDOM: FEATURES AND DIRECTIONS OF DEVELOPMENT}

N. Kadol

Summary. Object: The aim of this work is to analyze the social entrepreneurship development in United Kingdom, identify its characteristic features and directions of development.

Methods. To achieve the stated goal the methods of scientific knowledge were used: analysis of theoretical sources, analysis of regulatory legal acts, causal analysis, classification, and structural and functional analysis, abstraction, analysis, synthesis, and description

Findings. The analysis of the experience of social entrepreneurship development in United Kingdom made it possible to state that it occupies a certain niche and is the subject of providing social services, solves various problems of society.

Conclusions. The social entrepreneurship sector is quite young and provides opportunities for innovation and growth. Its activities are diverse, creative, and focused on socially important areas.

Keywords: business, social business, social entrepreneur, social responsibility, economic development, socially area.

\author{
Кадол Наталья Федоровна \\ К.э.н., докторант, Российская академия народного \\ хозяйства и государственной службы при Президенте \\ Российской Федерачии, Москва \\ NKadol@yandex.ru
}

Аннотация. Цель: Целью статьи является анализ развития социального предпринимательства в Великобритании, выявление его характерных особенностей и направлений развития.

Методы. Для достижения поставленной цели в работе были применены методы научного познания: анализ теоретических источников, анализ нормативных правовых актов, причинно-следственный анализ, структурно-функциональный анализ, абстрагирование, синтез, описание.

Результаты. Анализ опыта развития социального предпринимательства В Великобритании позволил констатировать, что оно занимает определенную нишу и является субъектом предоставления социальных услуг, решает различные проблемы общества.

Выводы. Сектор социального предпринимательства является достаточно молодым и предоставляя возможность для инноваций и роста Его деятельность разнообразна, креативна и сосредоточена в общественно значимых сферах.

Ключевые слова: предпринимательство, социальное предпринимательство, социальные предприниматель социальная ответственность, экономическое развитие, социальная сфера.

задач является идентификация сущности социального предпринимательства и его экономического содержания, выявление его концептуальных оснований. Важность и необходимость решения данной задачи отчасти связано с тем, что данное явление включает социальную и экономическую сферы предпринимательской деятельности. Поэтому необходимо обратиться к генезису сущности этого экономического понятия.

\section{Материалы и метолы}

В работе были использованы такие методы теоретического научного познания как анализ теоретических источников, анализ нормативных правовых актов, причинно-следственный анализ, структурно-функциональный анализ, абстрагирование, синтез, описание. Указанные методы послужили основанием исследования теоретической базы данного явления, а также эмпирической составляющей. 


\section{Аитературный обзор}

Появление и введение в научный оборот термина «социальное предпринимательство» связано прежде всего с такими именами, как Билл Дрейтон, основатель фонда «Ашока», который охарактеризовал данное направление деятельности как практичные и ориентированные на результат методы бизнес-деятельности с целью получения социального эффекта [6], а также Грегори Дизом, который впервые упомянул о данном явлении в академической литературе. Так, социальное предпринимательство он рассматривал как «использование методов традиционного предпринимательства для достижения социальных целей или выполнения социальной миссии. Социальный предприниматель выступает агентом изменений в социальной сфере» [5].

Анализ многочисленных зарубежных источников, посвященных проблематике социального предпринимательства, позволил выделит основные направления исследований в контексте определения ключевых понятий. Определенного внимания заслуживают работы Dees J. G. Defourny J., Nyssens M., Thompson J., Doherty B., Mair J., Marty I. Martin R.L., Osberg S. Boschee J., McClurg J. Alter K., Alvord S., Brown L., Letts C. В данных работах были предприняты попытки определить основные понятийные элементы данной области исследования, а именно: социальное предпринимательство, социальный предприниматель и социальные инновации. Следует отметить, что анализ различных определений социального предпринимательства, которые встречаются в экономической литературе, не позволяет выявить видимую границу между социальным предпринимательством и другими экономическими агентами [2].

\section{Результаты}

В Великобритании социальное предпринимательство реализуется через деятельность социальных предприятий. Согласно определению Ассоциации социальных предприятий Великобритании «социальное предприятие - это самостоятельная, прозрачная и подотчетная организация с четкой социальной и (или) экологической миссией, которая генерирует большую часть своих доходов за счет продажи собственных товаров и (или) услуг и реинвестирует большую часть своей прибыли» [9]. Таким образом сфера социального предпринимательства в Великобритании представлена различными организационно-правовыми формами. На основании исследований, проводимых Ассоциацией социальных предприятий Великобритании в разный период времени можно выделить основные правовые формы социальных предприятий. К ним относятся: Компания с ответственностью, ограниченной гарантиями (Company Limited by Guarantee (CLG)), Компания общественных интересов
(Community Interest Company (CIC)), Компания с ответственностью, ограниченной акциями (Company Limited by Shares (CLS)), Индустриальные и сберегательные общества (Industrial and Provident Society (IPS)) [1, с. 64].

Рассмотрим основные направления развитие социального предпринимательства и его вклад в экономику Великобритании. Для населения Великобритании характерна активная гражданско-социальная позиция в жизни общества. По данным исследования, проведённого лондонской сетью социального предпринимательства, было отмечено, что более 70\% жителей занимаются благотворительной деятельностью путем осуществления пожертвований. Социологические исследования, проводившиеся среди жителей Великобритании, показали, что примерно половина населения хотя бы один раз в месяц принимает участие в различных добровольных акциях, которые носят социально-экономический или природоохранный характер. По данным Нового экономического фонда, около 1,5 млн. людей в Великобритании регулярно участвуют в общественных экономических организациях. Начиная с 1995 года, наблюдается положительная динамика роста количества зарегистрированных благотворительных и общественных организаций. В 2006 г. на территории Великобритании функционировало почти 170 тыс. зарегистрированных благотворительных организаций, в состав которых входило более 20 тыс. дочерних компаний и около 11 тыс. незарегистрированных организаций. Годовой доход от деятельности, осуществляемой такими организациями, варьируется от $£ 1000$ до $£ 10$ млн. фунтов стерлингов [9].

По данным исследования Ассоциации социальных предприятий Великобритании численность организаций социального предпринимательства составляет 5\% от всех предприятий. В 2018 году здесь насчитывалось около 70 тысяч социально-ориентированных организаций, где работало почти 1 млн. человек, а в 2019 году порядка 100 тысяч [4]. Общее количество предприятий и организаций, которые были зарегистрированы как компании общественных интересов, по данным на 2013 год составило порядка 8 тысяч. По данным социологических исследований, проведенных в Великобритании, их общий годовой оборот достигает $£ 27$ млрд., а их вклад в ВВП страны составляет порядка $£ 8,4$ млрд. Предполагается, что в Лондоне существует около 30 тысяч организаций третьего сектора [9]. Изучение количественного состава 3700 общественных предприятий Великобритании показало, что на них было создано порядка 42 тысяч рабочих мест с товарооборотом в 1 млрд. фунтов и эти предприятия привлекли к работе приблизительно 60 тысяч добровольцев [9].

В Великобритании функционирует порядка 8 тысяч кооперативов (большая часть из которых являются 
сельскохозяйственные, потребительские, производственные), а также обществ взаимопомощи. Их членами являются более 19 млн. граждан. Кроме того, сюда относятся 567 кредитных союзов, членами которых являются порядка 5 млн. граждан [9]. Функционирование и развитие подобных организаций способствует сплоченности общества, делает его не равнодушным к имеющимся социальным проблемам, предоставляют возможность гражданам активно участвовать в решении этих проблем. Социальные предприятия благодаря проекции положительного опыта осуществления предпринимательской деятельности способны решить ряд общественных проблем как социальных, так и экологических.

Деятельность подобных организаций весьма популярна и активно поддерживается гражданами. Об этом свидетельствует рост количества населения, предпочитающего приобретать товары и услуги, которые были произведены организациями, акцентирующими свое внимание на защите окружающей среды и других социально-значимых проблемах.

С точки зрения содержательной структуры роль социальных предприятий выходит за рамки создания рабочих мест. В настоящее время особое внимание уделяется роли социального предпринимательства В повышении конкурентоспособности экономически и определении новых возможностей предоставления социально-значимых услуг населению. Деятельность социальных предприятий заинтересовано в развитии общественной экономики и способствует этому. В этой связи, осуществляемые социальные программы и деятельность социальных предприятий ориентируются на повышении эффективности всех форм работы (производства) и благосостояния, оплачиваемых и неоплачиваемых, в денежном выражении или натуральной форме, путем стимулирования и развития различных форм творческой деятельности, в которой все трудоспособные местные жители желают участвовать. Кроме того, такая деятельность способствует обучению и переподготовке работников, повышению их квалификации.

Еще одним из источников информации о состоянии и направлениях деятельности социального предпринимательства на территории Великобритании являются исследования, которые проводятся Ассоциацией социальных предприятий Великобритании.

Данные этих исследований за разные периоды времени демонстрируют определенную тенденцию развития данного сектора. Так, можно отметить, что основная доля социальных предприятий приходиться на стартапы и молодые предприятия, а также устоявшиеся предприятия, которые работают более 20 лет. Результаты ис- следования, проведенные в 2019 году, показывают, что данная тенденция в целом сохраняется.

Доля молодых предприятий и стартапов остаётся достаточно высокой. Порядка $30 \%$ социальных предприятий, участвующих в исследовании были созданы в течение последних трех лет [4]. В то время как в 2017 году они составляли $25 \%$. Почти четверть организаций социального предпринимательства существует на протяжении более 21 года [12].

Таким образом можно сделать вывод, что сектор социального предпринимательства является достаточно молодым и предоставляя возможность для инноваций и роста.

Основываясь на данных исследований, выполненных Ассоциацией социального предпринимательства Великобритании, можно констатировать, что социальное предпринимательство активно развивается в различных областях. Его деятельность разнообразна, креативна и решает различные проблемы общества. Его направления деятельности представлены в следующей таблице.

Приоритетными направлениями развития социального предпринимательства по результатам исследования за 2019 год являются: сфера образования, гостиничный бизнес и туризм, розничная торговля. Доля предприятий занятых в сфере образования составила 13\%, что на 2\% больше, чем в 2017 году. Также наблюдается рост доли социальных предприятий в сфере гостиничного бизнеса и туризма с 7\% в 2017 году до 10\% в 2019 году. Что касается сферы розничной торговли то здесь наблюдается противоположная тенденция. Доля предприятий в данной сфере сократилась с 16\% до $9 \%[4]$.

Если сравнивать данные исследования за 2019 год с исследованиями за 2017 и 2015 года, то можно констатировать, что проблемы трудоустройства и оказания услуг в сфере здравоохранения и социальной помощи стали менее актуальными и их доля снизилась в два раза в 2019 году по сравнению с данными прошлых периодов. Однако следует отметить, что в 2019 году отметили новые сферы деятельности социального предпринимательства, которые раньше в отдельную категорию не выделялись. К ним относятся Коммунальные услуги IT-консалтинг и разработка программного обеспечения, Услуги в сфере энергетики. Доля социальных предприятий, задействованных в данных сферах, составляет 4\%, $3 \%$ и $2 \%$ соответственно [4].

Таким образом, на основании вышеизложенного материала можно сделать вывод о том, что происходит смена приоритетов и сфер, в которых предпочитают 
осуществлять свою деятельность социальные предприниматели.

Основным источником денежных поступлений для социальных предприятий Великобритании являются доходы, полученные от предпринимательской деятельности. Более 75\% полученных доходов в общей структуре доходов составляют средства от реализации продукции у $77 \%$ социальных предприятий.

Весьма характерным примером работы социального предпринимательства в сфере занятости в Великобритании является деятельность английского журнала Big Issue [11]. Он занимается трудоустройством бездомных людей. Данный журнал предоставляет им работу. Бездомные занимаются распространением журналов, что дает им возможность получать заработную плату.

В инструкции по приему на работу предполагается: «... чтобы заниматься распространением журнала, человек должен подтвердить, что он является бездомным или находится под угрозой бездомности. После этого такой человек должен пройти процедуру приема и подписать правила поведения. После этого человеку выдается несколько бесплатных экземпляров журнала. После продажи выданных журналов он может приобрести новые экземпляры за 1,25 фунта, которые он в последующем может их реализовать по цене 2,5 фунта. Благодоря этой разнице цены бездомный может заработать 1,25 фунта с каждого проданного экземпляра журнала» [11]. Учредители данной организации отмечают, что «данная модель получения дохода бездомными позволяет им осознать ответственность за свою жизнь. Они становятся мини-предпринимателями и получают определенные навыки осуществления продаж. Все это в дальнейшем будет способствовать их социализации и интеграции в жизнь общества» [11].

Учредители организации часть денежных средств, полученных от реализации журнала, направляют на его развитие и покрытие текущих затраты. Оставшиеся денежные ресурсы идут в специальный фонд Big Issue, который в дальнейшем за счет этих средств оказывает необходимую помощь бездомным людям. Например, данный фонд оказывает консультационные услуги бездомным людям по проблемам, с которыми они сталки- ваются. Также он помогает с медицинской помощью, жильем, образовательными программами. Кроме того, Фонд может оказывать и прямую материальную поддержку, например, «если бездомному требуется купить что-то для возвращения в общество, он может внести часть суммы (20\%), остальное предоставляет фонд» [11].

Еще одним примером деятельности социального предпринимательства великобританского общества является деятельность социального предприятия в сфере экологии - Eden Project. Благодаря деятельности предприятия был разбит сад в тропических биосистемах, в которых выращиваются растения из различных климатических зон. На базе этой организации осуществляются экскурсии, концерты различных музыкантов, кроме того, проводят занятия. Здесь функционирует магазин, в котором продаются органические продукты питания [1, с 72].

Другая организация Doncaster Refurnish занимается производством доступной мебели для малоимущих и социально-уязвимых слоёв населения. Кроме того, она осуществляет ремонт, а также реставрацию старой мебели, которую люди уже не используют и выбрасывают. Полученные доходы организация реинвестирует в развитие местных социальных проектов.

\section{Зак^ючение}

Практика развития социального предпринимательства в Великобритании показывает, что данная деятельность активно развивается и вносит определенный вклад в развитие экономики. Оно является уже неотъемлемым элементом и одним из ресурсов социально-экономического развития. Данный сектор является достаточно молодым и предоставляя возможность для инноваций и роста. Его значимость с позиции регионального экономического развития связана с решением социально-значимых проблем общества, основной из которых является обеспечение занятости местного населения и содействие его самозанятости. Анализ опыта развития социального предпринимательства в Великобритании позволил констатировать, что оно занимает определенную нишу и является субъектом предоставления социальных услуг, решает различные проблемы общества. Его деятельность разнообразна, креативна и сосредоточена в общественно значимых сферах.

\section{ЛИТЕРАТУРА}

1. Институциональные основы развития социального предпринимательства: зарубежный опыт: Монография / Под ред. Л. В. Дуканич. — Москва: МАКС Пресс, 2020.- 140 c.

2. Кадол Н. Ф. Становление и идентификация социального предпринимательства в мировой практике / Н. Ф. Кадол // Лидерство и менеджмент.- 2020.Том 7.— № 2.— doi: 10.18334/lim.7.2.110501.

3. Ashoka: What is a social entrepreneur? [Электронный ресурс]: Режим доступа: http://www.ashoka.org/ fellows/social_entrepreneur.cfm. 
4. Capitalism in Crisis? Transforming our Economy for People and Planet — SOSE2019 [Электронный ресурc]. URL: https://www.socialenterprise.org.uk/state-ofsocial-enterprise-reports/

5. Dees, J. G. The meaning of social entrepreneurship [Электронный ресурс]: (original draft: 1998, revised 2001) / J. Gregory Dees // Duke University, the Fuqua School of Business. — 2001.— — Режим доступа: http://www.caseatduke.org/documents/dees_sedef.pdf.

6. Drayton, B. Social Entrepreneurs: creating a competitive and entrepreneurial citizen sector. [Электронный ресурс].— Режим доступа: at: http://www. changemakers.net/library/readings.

7. Leading the world in social enterprise — State of Social Enterprise Survey 2015 [Электронный ресурc]. URL: https://www.socialenterprise.org.uk/state-of-socialenterprise-reports/

8. Social Enterprise Coalition [Электронный ресурc]. URL: http://www.socialenterprise.org.uk/Default.aspx

9. Social Enterprise UK [Электронный ресурс].— Режим доступа: https://www.socialenterprise.org.uk/

10. Social Enterprise UK. The people's business — State of Social Enterprise Survey 2013 [Электронный ресурc]. URL: https://www.socialenterprise.org.uk/state-ofsocial-enterprise-reports/.

11. The Big Issue Foundation [Электронный ресурc]. URL: http://www.bigissueonline.com/cgi-bin/foundation/index.html

12. The Future of Business — State of Social Enterprise Survey 2017 [Электронный ресурc]. URL: https://www.socialenterprise.org.uk/state-of-social-enterprisereports/

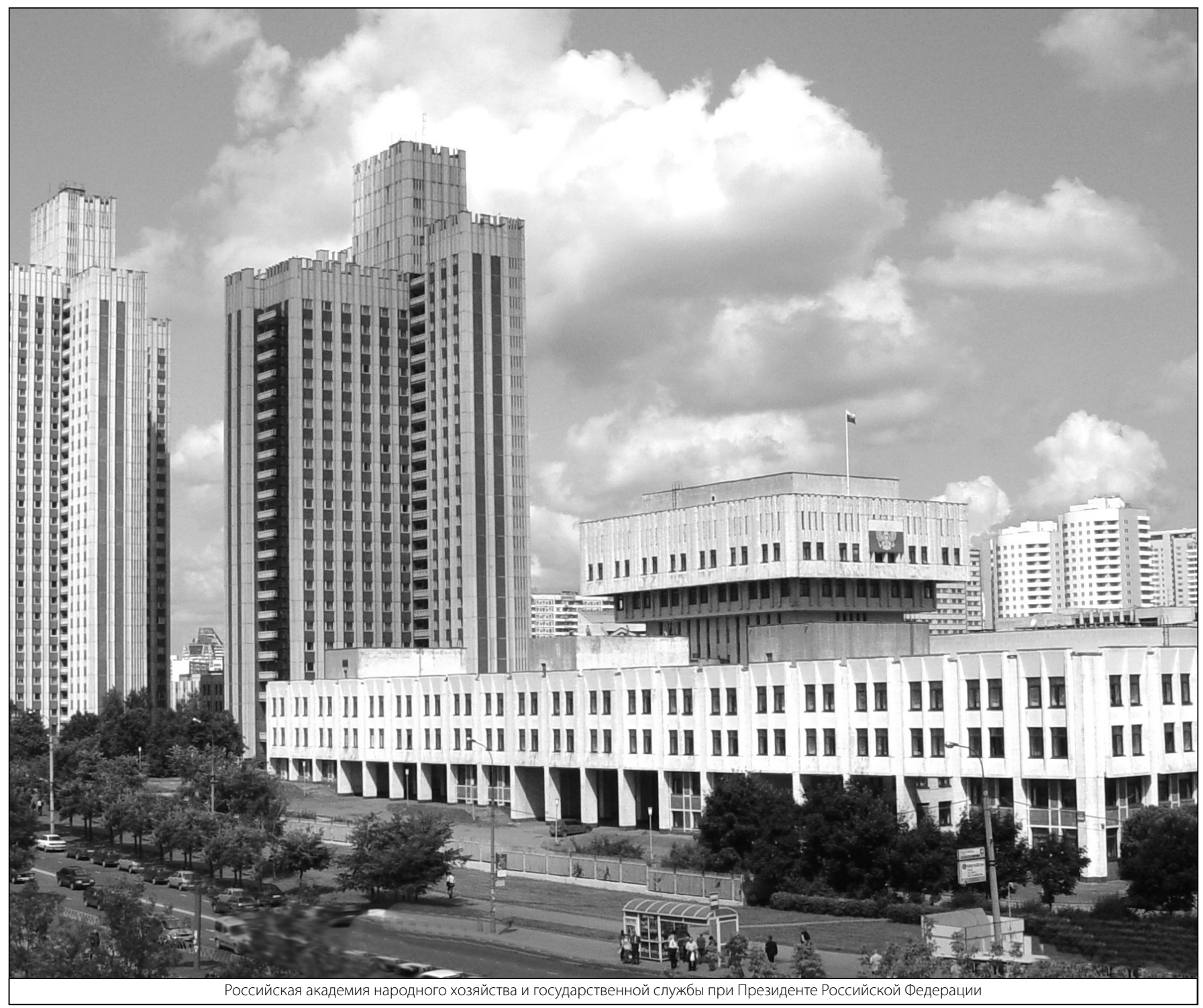

